Research Article

\title{
Development of Empirical Fragility Curves in Earthquake Engineering considering Nonspecific Damage Information
}

\author{
Jung J. Kim (i) \\ Professor, Department of Civil Engineering, Kyungnam University, Changwon-si 51767, Republic of Korea \\ Correspondence should be addressed to Jung J. Kim; jungkim@kyungnam.ac.kr
}

Received 3 September 2018; Revised 4 November 2018; Accepted 11 November 2018; Published 13 December 2018

Guest Editor: Tiago Ferreira

Copyright (c) 2018 Jung J. Kim. This is an open access article distributed under the Creative Commons Attribution License, which permits unrestricted use, distribution, and reproduction in any medium, provided the original work is properly cited.

\begin{abstract}
As a function of fragility curves in earthquake engineering, the assessment of the probability of exceeding a specific damage state according to the magnitude of earthquake can be considered. Considering that the damage states for fragility curves are generally nested to each other, the possibility theory, a special form of the evidence theory for nested intervals, is applied to generate fragility information from seismic damage data. While the lognormal distributions are conventionally used to generate fragility curves due to their simplicity and applicability, the methodology to use the possibility theory does not require the assumption of distributions. Seismic damage data classified by four damage levels were used for a case study. The resulted possibility-based fragility information expressed by two monotone measures, "possibility" and "certainty," are compared with the conventional fragility curves based on probability. The results showed that the conventional fragility curves provide a conservative estimation at the relatively high earthquake magnitude compared with the possibility-based fragility information.
\end{abstract}

\section{Introduction}

In earthquake engineering, fragility curves have been used to estimate damages of infrastructures according to the magnitude of earthquake. While fragility curves can provide reasonable estimation of earthquake damages with damage levels, those might neglect the possible slight damage occurrence at the relatively low earthquake magnitude due to the nature of probability density functions consists of two parameters, expected mean value and dispersion.

Traditionally, probability theory has been used to model uncertainties in structural engineering, especially when addressing reliability for structural safety $[1,2]$. However, the types of uncertainties considered in probability theory are random, chance, and likelihood, and there are limitations to model other types of uncertainties such as nonspecificity, fuzziness, and strife, using probability theory $[3,4]$. Random uncertainty known as aleatory uncertainty is from inherent randomness and therefore is irreducible. However, other types of uncertainties known as epistemic uncertainties arise from lack of knowledge and therefore are reducible and subjective. Research on generalized information theory (GIT)
$[5,6]$ showed that three types of epistemic uncertainties due to lack of knowledge and/or variability thrive when modeling complex environments [7]. While nonspecificity represents the difficulty to choose from many modeling alternatives, fuzziness represents the uncertainty due to lack of sharpness (imprecise boundaries) of the modeling parameter. Strife expresses the uncertainty due to conflict among alternatives. Given are there various types of uncertainties, appropriate modeling of uncertainty has been an interesting and challenging topic in many areas during the last few decades [8-10]. A number of theories to model uncertainties adequately have been introduced: evidence theory $[11,12]$, possibility theory $[3,13]$ and fuzzy set theory $[14,15]$.

In earthquake engineering, empirical fragility curves were generally presented in the form of lognormal cumulative distribution function (CDF) with respect to peak ground acceleration (PGA) representing the ground motion intensity due to earthquake [16]. To generate empirical fragility curve for a damage state, the damage reports by experts are used. The damage reports usually present the damage states in linguistic ways such as "no damage," "slight damage," "moderate damage," "extensive damage," and 
"collapse" for a structure experiencing earthquake of a PGA. As the fragility curve of a damage state represents the fragility of "at least" of the damage level, the evidence for a damage state includes possible higher damage states. For example, the evidence for "moderate damage" of a structure by an earthquake means that the structure is damaged at least moderately, and it might be possible for the structure to be damaged extensively or collapsed. As there exist ambiguous boundaries between the damage states, fuzzy logic and possibility theory were applied to resolve the ambiguity $[17,18]$.

Recently, extensive earthquake damage data are used to generate fragility curves [19-25]. Postearthquake surveys of approximately 340000 reinforced concrete structures were used to derive fragility curves for a European seismic risk assessment scenario [19]. A database of 7597 reinforced concrete buildings located in the city and the province of L'Aquila in Italy was used in order to derive fragility curves [20]. The observed damage to 9500 of low-rise residential buildings from earthquakes in South Iceland was studied by typological fragility curves [21]. Moreover, fragility curves were developed from millions of data on the basis of 665,515 building damage cases by earthquake in Nepal [22, 23]. In Italy, the postearthquake damage surveys of approximately 90,000 buildings in order to derive fragility curves were considered $[24,25]$. Even with the increase of damage data to generate fragility curves, there is still an uncertainty of nonspecificity, the difficulty to choose from many modeling functions of fragility curves such as lognormal, extreme type I, extreme type II functions, and so on.

In this study, the evidence of damage state is dealt with possibility theory. It is noticeable that the fragility curves from possibility distribution representing the certainty of damage state and those are generated without any assumption of distributions. Therefore, there is no uncertainty of nonspecificity to choose functions of fragility curves.

\section{Possibility Information in Fragility Curves}

Theories for modeling uncertainties present different types of uncertainty assignment and monotone measures. As uncertainty assignment terms, the degree of belief, probability distribution, and possibility distribution are used for evidence theory, probability theory, and possibility theory, respectively. To quantify the assigned uncertainties, monotone measures are used such as dual monotone measures of plausibility and belief, dual monotone measures of possibility and certainty, and single monotone measure of probability for evidence theory, probability theory, and possibility theory, respectively [26-28]. Considering the relationship between uncertainty assignment terms and monotone measures used for each theory, it can be known as probability theory and possibility theory are special forms of evidence theory [6]. Consider a discrete universe $D$ that consists of a set of damage levels,

$$
D=\left\{d_{\mathrm{N}}, d_{\mathrm{S}}, d_{\mathrm{M}}, d_{\mathrm{E}}, d_{\mathrm{C}}\right\},
$$

where $d_{\mathrm{N}}, d_{\mathrm{S}}, d_{\mathrm{M}}, d_{\mathrm{E}}$, and $d_{\mathrm{C}}$ represent no damage, slight damage, moderate damage, extensive damage, and collapse of a structure due to a seismic force level respectively.
In evidence theory, which is also known as Dempster-Shafer theory $[11,12]$, the degree of belief $m$ based on evidence is assigned to all countable subsets $\mathrm{A}$ (e.g., $\varnothing,\left\{d_{\mathrm{N}}\right\},\left\{d_{\mathrm{N}}, d_{\mathrm{S}}\right\}, \ldots,\left\{d_{\mathrm{N}}, \ldots, d_{\mathrm{C}}\right\}$ ) with the constraint of

$$
\sum_{A \subset D} m(A)=1 \text {. }
$$

Dual monotone measures, belief bel $(A)$ and plausibility $\mathrm{pl}(A)$, for a subset $A$ are calculated as

$$
\begin{aligned}
\operatorname{bel}(A) & =\sum_{B \in A} m(B), \\
\operatorname{pl}(A) & =\sum_{B \cap A \neq \varnothing} m(B) .
\end{aligned}
$$

While belief measure represents the degree of evidence for a subset $A$, plausibility measure is defined as "Complement of the belief of the complement of a subset $A$ " as

$$
\operatorname{pl}(A)=1-\operatorname{bel}(\bar{A}) .
$$

As belief measure is based on the degree of belief with its evidence, belief measure of "Complement of a subset $A$ " also needs its evidence. Therefore, if there is no evidence for "Complement of a subset $A$," one cannot determine the belief of "Complement of a subset $A$ " as 1-bel $(A)$. The difference between these two measures can represent our ignorance (lack of knowledge) of a subset $A$ (denoted ign) as

$$
\operatorname{ign}(A)=\operatorname{pl}(A)-\operatorname{bel}(A)=1-[\operatorname{bel}(\bar{A})+\operatorname{bel}(A)] \text {. }
$$

In probability theory, probability distribution, which is equivalent to the degree of belief $m$ in evidence theory, is assigned to a single variable (e.g. $d_{\mathrm{N}}, \ldots, d_{\mathrm{C}}$ ) on universe $D$ such as

$$
\sum_{d_{i} \in D} p\left(d_{i}\right)=1
$$

where $d_{i}$ denotes the damage state, $d_{\mathrm{N}}, d_{\mathrm{S}}, d_{\mathrm{M}}, d_{\mathrm{E}}$, and $d_{\mathrm{C}}$. Only one monotone measure, probability $\operatorname{prob}(A)$, for a subset $A$ is defined as

$$
\operatorname{prob}(A)=\sum_{d_{i} \in A} p\left(d_{i}\right)
$$

and probability measure of "Complement of a subset $A$ " is defined as

$$
\operatorname{prob}(\bar{A})=1-\operatorname{prob}(A),
$$

with the excluded middle axioms [4]. Unlike evidence theory, "Complement of a subset $A$ " can be determined as 1 - prob $(A)$. Therefore, our lack of knowledge measured by ign $(A)$ in equation (6) cannot be measured in probability theory.

In possibility theory, possibility distribution $\pi$ is assigned to a single damage level in possibility theory such as

$$
\begin{aligned}
\pi\left(d_{i}\right) & =\sum_{d_{i} \in A} m(A), \\
\max \left\{\pi\left(d_{i}\right)\right\} & =1 .
\end{aligned}
$$


The relationship between the uncertainty assignment $\pi$ and the degree of belief $m$ in equation (10) indicates that possibility theory is a special form of evidence theory when the collective body of evidence is consonant [26-28] (see Figure 1).

Dual monotone measures, certainty cert $(A)$ and possibility pos $(A)$, for a subset $A$ are determined as

$$
\begin{aligned}
& \operatorname{pos}(A)=\sup \left\{\pi\left(d_{i}\right): x_{i} \in A\right\}, \\
& \operatorname{cert}(A)=1-\operatorname{pos}(\bar{A}) .
\end{aligned}
$$

This relationship can be converted to a single measure that represents the degree of confirmation $\mathrm{C}(A)$ of a subset $A$, whose range is from -1 to 1 [5]:

$$
\mathrm{C}(A)=\operatorname{cert}(A)+\operatorname{pos}(A)-1 \text {. }
$$

Negative value of the degree of confirmation expresses the degree of disconfirmation of a subset $A$. It is noticeable that the assignment of possibility distribution of 1 to a single variable means that the occurrence of the variable is possibly 1 but certainly "no evidence," while the assignment of degree of possibility of zero confirms that the occurrence of the variable is possibly zero and certainly zero. For a consonant body of evidence, the following relationship for two different subsets, $A$ and $B$, can be proven [6]:

$$
\begin{aligned}
& \operatorname{pos}(A \cup B)=\max [\operatorname{pos}(A), \operatorname{pos}(B)], \\
& \operatorname{cert}(A \cap B)=\min [\operatorname{cert}(A), \operatorname{cert}(B)] .
\end{aligned}
$$

When the ignorance in equation (6) is zero, the excluded middle axioms are satisfied and the evidence can be described using one monotone measure called the probability measure. Moreover, when body of evidence is consonant, monotone measures in evidence theory, belief and plausibility, can be represented as those in possibility theory, certainty and possibility, respectively (see Appendix for examples).

As the fragility curve of a damage state represents the fragility of "at least" of the damage level, probable damage information for higher damage state is included in a damage state. For example, the evidence for "no damage" means that a structure seems undamaged, but there might be possible damages for the structure: slight, moderate, extensive, or collapsed damages. Considering the characteristics of evidence, "at least," we can define subsets $N, S, M, E$, and $C$ for "at least no damage," "at least slight damage," "at least moderate damage," "at least extensive damage," and "at least collapse" as shown in equation (16). It can be recognized that a damage subset includes higher than and equal to the damage levels.

$$
\begin{aligned}
N & =\left\{d_{N}, d_{S}, d_{M}, d_{E}, d_{C}\right\}, \\
S & =\left\{d_{S}, d_{M}, d_{E}, d_{C}\right\}, \\
M & =\left\{d_{M}, d_{E}, d_{C}\right\}, \\
E & =\left\{d_{E}, d_{C}\right\}, \\
C & =\left\{d_{C}\right\} .
\end{aligned}
$$

It is seen that the subsets in equation (16) are nested to each other such as $C \subset E \subset M \subset S \subset N$. Based on the degree

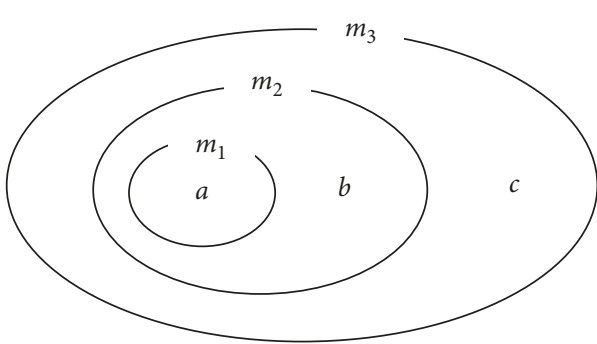

Figure 1: Consonant body of evidence.

of belief, $m$ is assigned to a consonant set of damage levels, possibility distributions for predetermined PGA region are generated using the assignment of the degree of belief. The sequence of monotone measures of each damage level with respect to PGA is presented and compared with conventional fragility curves generated by maximum likelihood estimation. It is noticeable that the evidence for at least no damage, $N$, is considered as any damage level.

\section{Case Study}

A schematic representation of the proposed framework to generate fragility curves using possibility distributions is shown in Figure 2. At the first step, the empirical damage data are rearranged in the shape of binomial damage data for damage states. In this step, the damage data are rearranged in the ascending order with respect to PGA. As this procedure is out of scope of this study, the arranged data by other researchers [16] are used for case study. Some part of the arranged data is presented in Table 1. Using the arranged data set, PGA intervals are determined based on the inclusion of damage levels at the second step. At the third step, the degree of belief $m$ is assigned to the sets in equation (16) based on the occurrence of damage levels in each PGA interval. At the fourth step, possibility distribution is generated based on the degree of belief. At the final step, monotone measures for PGA intervals are calculated and the sequence of monotone measures with respect to PGA is determined.

For the case study, the damage data of bridges from the 1994 Northridge earthquake are used to develop empirical fragility curves [16]. The PGA value at the location of bridges is interpolated and extrapolated from the PGA data [16]. The binomial damage information of damage states "no damage," "at least minor," "at least moderate," "at least major," and "collapse" in original reference [16] are used to generate possibility-based empirical fragility curves of "no damage fragility curve," "slight damage fragility curve," "moderate damage fragility curve," "extensive damage fragility curve," and "collapse fragility curve," respectively, in this study.

For the comparison, the binomial information for the damage state at PGA is used to generate empirical fragility curves by maximum likelihood estimation with the assumption of lognormal and extreme type I and II distributions. The results of the four families of fragility curves are presented in Figure 3. 


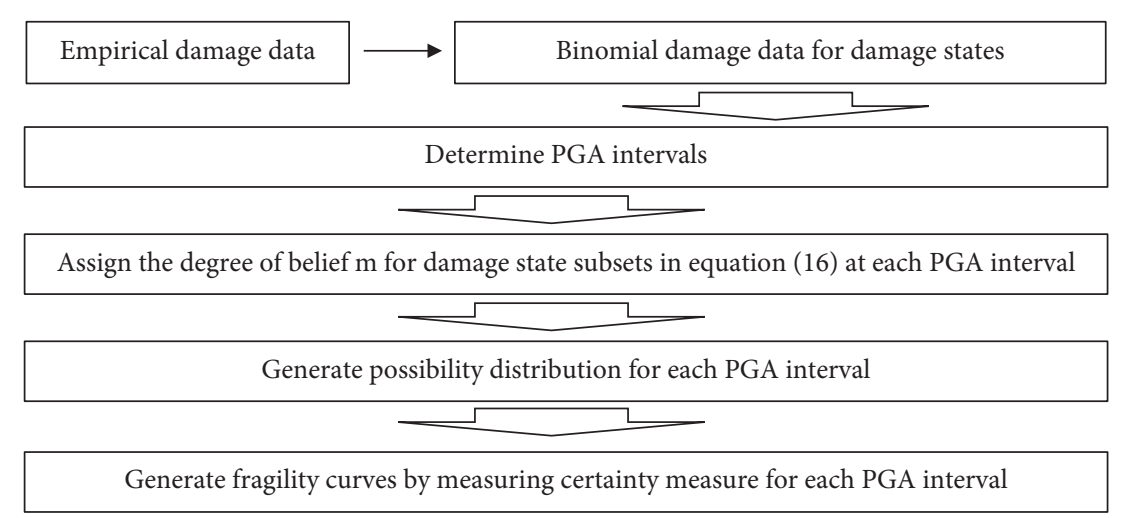

FIgURE 2: Procedure to generate empirical fragility curves using possibility distributions.

TABle 1: Some part of the arranged binomial data to generate empirical fragility curves for the case study [16].

\begin{tabular}{cccccccc}
\hline No. & PGA & None & $\geq$ Min & $\geq$ Mod & $\geq$ Maj & $\geq$ Col & $\begin{array}{c}\text { First } \\
\text { appearance }\end{array}$ \\
\hline 1 & 0.069 & 1 & 0 & 0 & 0 & 0 & \\
$\vdots$ & $\vdots$ & $\vdots$ & $\vdots$ & $\vdots$ & $\vdots$ & $\vdots$ & \\
57 & 0.079 & 1 & 0 & 0 & 0 & 0 & \\
$\vdots$ & $\vdots$ & $\vdots$ & $\vdots$ & $\vdots$ & $\vdots$ & $\vdots$ & \\
62 & 0.080 & 1 & 1 & 0 & 0 & 0 & Minor damage \\
$\vdots$ & $\vdots$ & $\vdots$ & $\vdots$ & $\vdots$ & $\vdots$ & $\vdots$ & \\
397 & 0.137 & 1 & 0 & 0 & 0 & 0 & \\
$\vdots$ & $\vdots$ & $\vdots$ & $\vdots$ & $\vdots$ & $\vdots$ & $\vdots$ & \\
415 & 0.138 & 1 & 1 & 1 & 0 & 0 & Moderate \\
$\vdots$ & $\vdots$ & $\vdots$ & $\vdots$ & $\vdots$ & $\vdots$ & $\vdots$ & \\
1303 & 0.322 & 1 & 0 & 0 & 0 & 0 & \\
$\vdots$ & $\vdots$ & $\vdots$ & $\vdots$ & $\vdots$ & $\vdots$ & $\vdots$ & \\
1307 & 0.323 & 1 & 1 & 1 & 1 & 0 & Major damage \\
$\vdots$ & $\vdots$ & $\vdots$ & $\vdots$ & $\vdots$ & $\vdots$ & $\vdots$ & \\
1555 & 0.384 & 1 & 0 & 0 & 0 & 0 & \\
$\vdots$ & $\vdots$ & $\vdots$ & $\vdots$ & $\vdots$ & $\vdots$ & $\vdots$ & \\
1561 & 0.385 & 1 & 1 & 1 & 1 & 1 & Collapse \\
$\vdots$ & $\vdots$ & $\vdots$ & $\vdots$ & $\vdots$ & $\vdots$ & $\vdots$ & \\
1859 & 0.680 & 1 & 1 & 1 & 1 & 0 & \\
1860 & 0.682 & 1 & 1 & 1 & 0 & 0 & \\
1861 & 0.682 & 1 & 1 & 1 & 1 & 1 & Collapse \\
$\vdots$ & $\vdots$ & $\vdots$ & $\vdots$ & $\vdots$ & $\vdots$ & $\vdots$ & \\
1998 & 0.889 & 1 & 1 & 1 & 1 & 0 & \\
\hline & & & & & & &
\end{tabular}

\section{Results and Discussions}

From the binomial information of damage state data, PGA intervals are determined based on the inclusion of damage levels and presented in Table 2. For the last PGA interval, it is divided into two regions as the first collapse evidence at PGA of $0.385 \mathrm{~g}$ seems possible, but the next evidence is far from the PGA such as $0.682 \mathrm{~g}$. During the $0.385 \mathrm{~g}$ to $0.682 \mathrm{~g}$, as there is no evidence for collapse, the PGA interval is divided for engineering sense.

Based on the occurrence of damage levels in each PGA interval, the degree of belief $m$ is assigned to the sets in equation (16) and presented in Table 3. The possibility distributions for each PGA intervals are generated as shown in Figure 4. The possibility distribution $\pi$ values for each damage level are calculated based on the degree of belief and presented in Table 4. For example, $\pi$ for $d_{M}$ for the interval $[0.385,0.680]$ is calculated as the summation of the degree of belief for $N, S, M$ in the respective interval of Table 3. It follows the definition of $\pi$ as presented in equation (10).

Using the generated possibility distributions in Figure 4, monotone measures for $N, S, M, E$, and $C$ can be measured. An example to measure the dual monotone measures in possibility theory, certainty $\operatorname{cert}(M)$ and possibility $\operatorname{pos}(M)$, for $M$ of the interval $[0.323,0.384]$ is presented in Figure 5. The maximum possibility distribution $\pi$ inside of the interval will be the measure of pos as $100 \%$ as defined in equation (11) and the complement of the maximum possibility distribution $\pi$ outside of the interval will be the measure of cert as $8 \%$ as defined in equation (12). The degree of confirmation is calculated using the dual monotone measures as $8 \%$ as shown in equation (13). The certainty and possibility measures are presented in Tables 5 and 6 , respectively. It is noticeable that the belief and plausibility measures for the sets in equation (16) are same with the certainty and possibility measures, respectively, as possibility theory is a special form of evidence theory. The belief and plausibility measures in evidence theory are presented in Tables 7 and 8.

As the possibility measures for all intervals are $100 \%$ as presented in Table 6, the degree of confirmation is going to be the same with the certainty measure in Table 5 . The empirical fragility curves can be constructed by plotting certainty or the degree of confirmation with respect to the corresponding intervals as shown in Figure 6.

Comparisons with the conventional fragility curves that generated by assuming a distribution are presented in Figures 7-10. It is noticeable that the caption for $y$-axis in the figures, "fragility" represents "probability" in probability theory and "certainty" in possibility theory. For the comparison of "Slight" damage state as shown in Figure 7, the conventional fragility curves underestimate the failure probability at the PGA interval between $0.323 \mathrm{~g}$ and $0.5 \mathrm{~g}$. For the comparison of "Moderate" and "Extensive" damage states as shown in Figures 8 and 9, respectively, the conventional fragility curves underestimate the failure probability at the PGA interval between $0.385 \mathrm{~g}$ and $0.5 \mathrm{~g}$. Finally, 


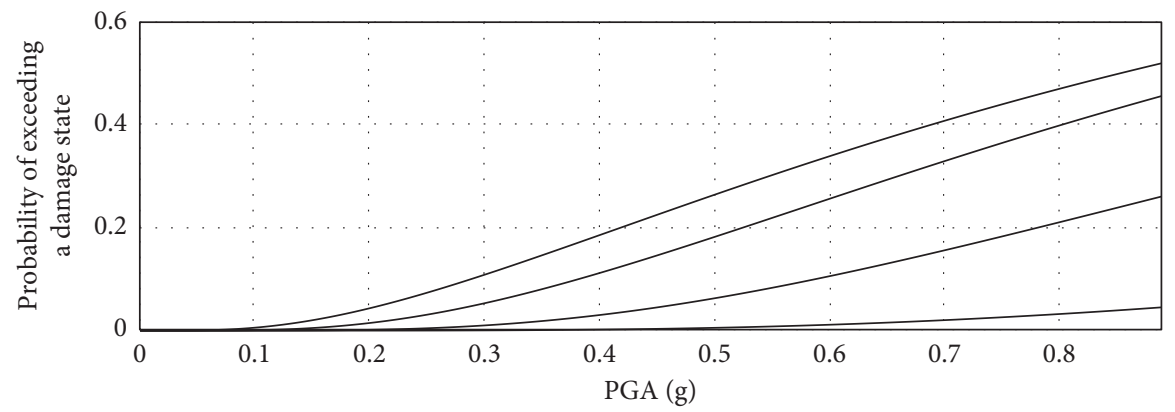

(a)

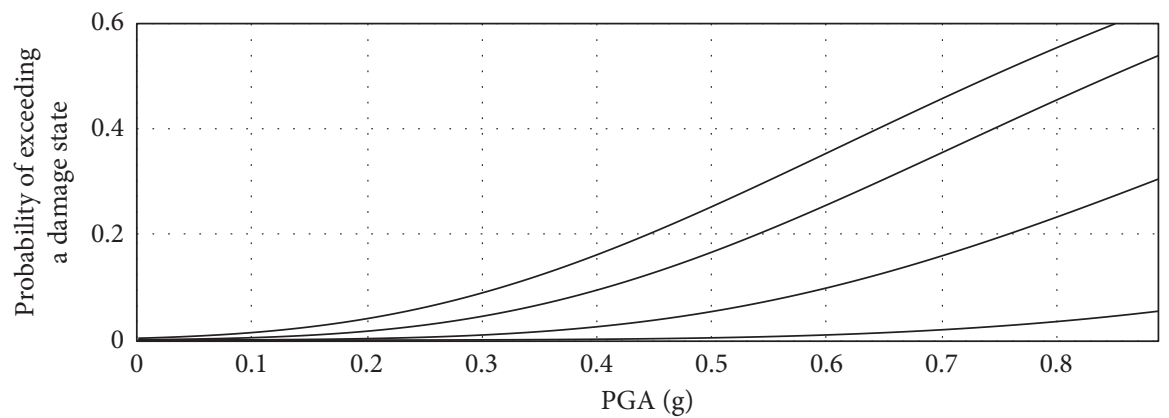

(b)

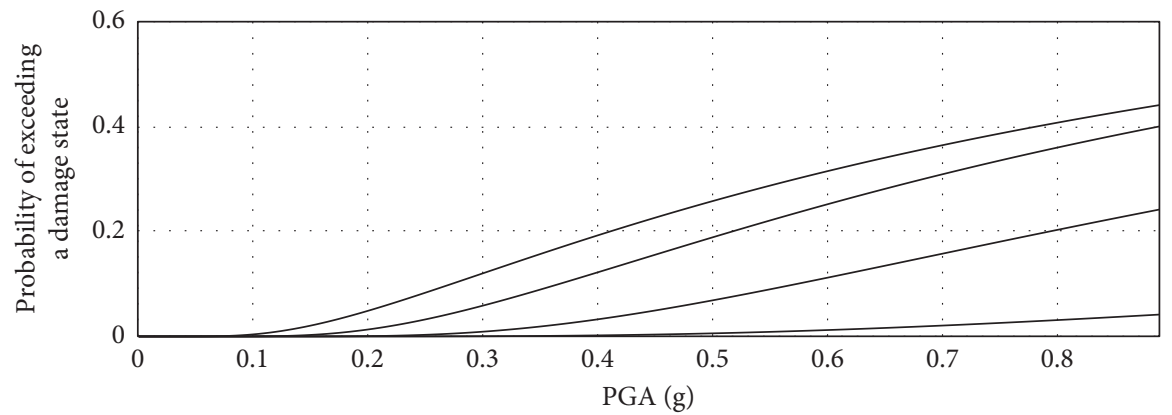

(c)

FIGURE 3: Empirical fragility curves determined by maximum likelihood estimation using different distribution functions. At each figure, curves from top to bottom are fragility curves for damage state subsets of $S, M, E$, and $C$, respectively. (a) Lognormal CDF. (b) Extreme type I (Gumbel) CDF. (c) Extreme type II (Frechet) CDF.

TABLE 2: Number of damage information at each damage state in PGA intervals.

\begin{tabular}{lcccccc}
\hline PGA interval $(\mathrm{g})\left[\theta_{1}, \theta_{2}\right]$ & None $(N)$ & Slight $(S)$ & Moderate $(M)$ & Extensive $(E)$ & Collapse $(C)$ & No. of evidence \\
\hline$[0.069,0.079]$ & 56 & 0 & 0 & 0 & 0 & 56 \\
{$[0.080,0.137]$} & 350 & 8 & 0 & 0 & 0 & 0 \\
{$[0.138,0.322]$} & 862 & 14 & 16 & 6 & 0 & 858 \\
{$[0.323,0.384]$} & 205 & 24 & 14 & 20 & 1 & 249 \\
{$[0.385,0.680]$} & 221 & 23 & 39 & 21 & 5 & 139 \\
{$[0.682,0.889]$} & 74 & 14 & 25 & 47 & 6 & 1998 \\
Sum & 1768 & 83 & 94 & & 0 \\
\hline
\end{tabular}

for the comparison of "Collapse" damage state as shown in Figure 10, the conventional fragility curves underestimate the failure probability at the PGA interval between $0.682 \mathrm{~g}$ and $0.8 \mathrm{~g}$. While there is no evidence for damage over the PGA of $0.889 \mathrm{~g}$, the conventional fragility curves for all damage states clearly overestimate the failure probability over the PGA of $0.889 \mathrm{~g}$. These results are obvious as the conventional fragility curves are generated by assuming the distributions with mathematical formulations such as lognormal and extreme type I and type II distributions.

With extensive earthquake damage database, the uniform PGA interval, so called as "PGA bin," can be used instead of the PGA intervals determined by experts in Table 2. In this case, the shape of fragility curve also can be 
TABLe 3: Degree of belief $m$ based on the fraction of each damage state in PGA intervals.

\begin{tabular}{|c|c|c|c|c|c|c|}
\hline PGA interval $(\mathrm{g})\left[\theta_{1}, \theta_{2}\right]$ & None $(N)$ & Slight $(S)$ & Moderate $(M)$ & Extensive $(E)$ & Collapse $(C)$ & Sum \\
\hline$[0.069,0.079]$ & 1.000 & 0.000 & 0.000 & 0.000 & 0.000 & 1.000 \\
\hline$[0.080,0.137]$ & 0.978 & 0.022 & 0.000 & 0.000 & 0.000 & 1.000 \\
\hline$[0.138,0.322]$ & 0.966 & 0.016 & 0.018 & 0.000 & 0.000 & 1.000 \\
\hline$[0.323,0.384]$ & 0.823 & 0.096 & 0.056 & 0.024 & 0.000 & 1.000 \\
\hline$[0.385,0.680]$ & 0.727 & 0.076 & 0.128 & 0.066 & 0.003 & 1.000 \\
\hline$[0.682,0.889]$ & 0.532 & 0.101 & 0.180 & 0.151 & 0.036 & 1.000 \\
\hline
\end{tabular}

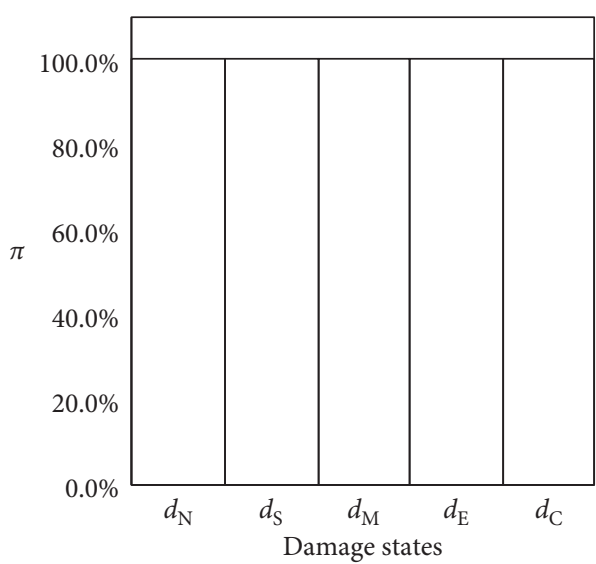

(a)

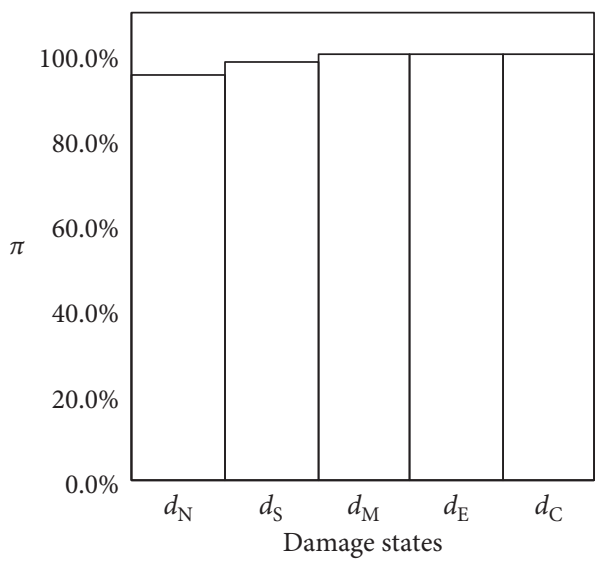

(c)

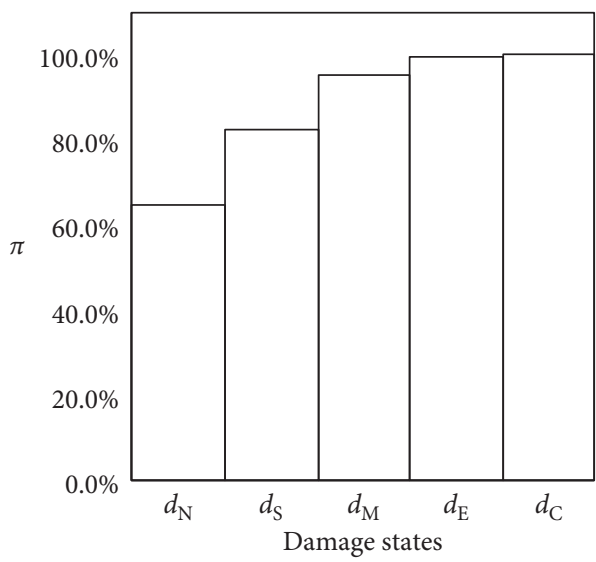

(e)

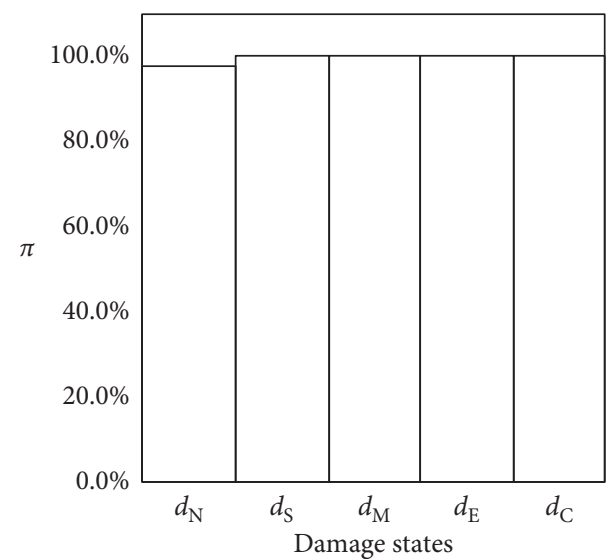

(b)

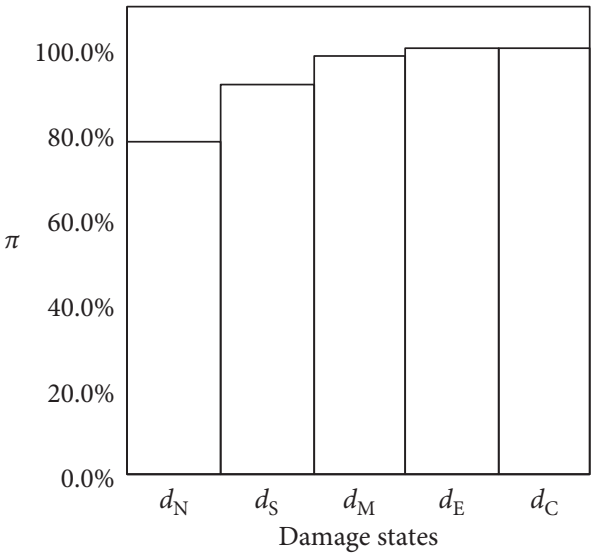

(d)

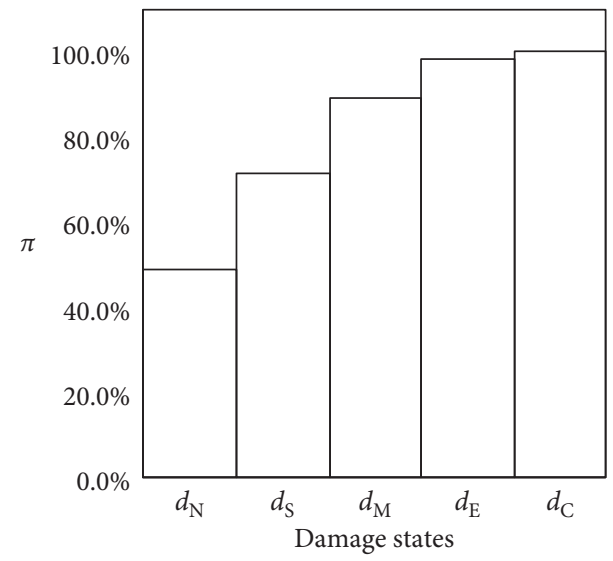

(f)

Figure 4: Possibility distributions of damage states for the corresponding PGA (g) intervals. (a) [0.069, 0.079]g. (b) [0.080, 0.137]g. (c) $[0.138,0.322]$ g. (d) $[0.323,0.384]$ g. (e) $[0.385,0.680]$ g. (f) $[0.682,0.889]$. 
TABLE 4: Assigning $\pi$ based on the degree of belief $m$ in Table 3 .

\begin{tabular}{|c|c|c|c|c|c|c|}
\hline PGA interval $(\mathrm{g})\left[\theta_{1}, \theta_{2}\right]$ & $d_{\mathrm{N}}(\%)$ & $d_{\mathrm{S}}(\%)$ & $d_{\mathrm{M}}(\%)$ & $d_{\mathrm{E}}(\%)$ & $d_{\mathrm{C}}(\%)$ & Max. (\%) \\
\hline$[0.069,0.079]$ & 100.0 & 100.0 & 100.0 & 100.0 & 100.0 & 100 \\
\hline$[0.080,0.137]$ & 97.8 & 100.0 & 100.0 & 100.0 & 100.0 & 100 \\
\hline$[0.138,0.322]$ & 96.6 & 98.2 & 100.0 & 100.0 & 100.0 & 100 \\
\hline$[0.323,0.384]$ & 82.3 & 92.0 & 97.6 & 100.0 & 100.0 & 100 \\
\hline$[0.385,0.680]$ & 72.7 & 80.3 & 93.1 & 99.7 & 100.0 & 100 \\
\hline$[0.682,0.889]$ & 53.2 & 63.3 & 81.3 & 96.4 & 100.0 & 100 \\
\hline
\end{tabular}

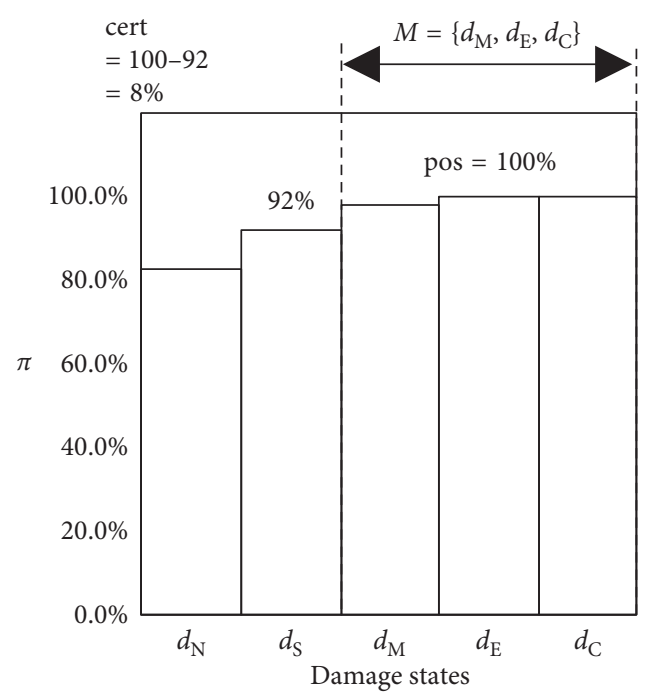

Figure 5: Calculated certainty measure, cert $=8 \%$, and possibility measure, pos $=100 \%$, of the set $M=\left\{d_{\mathrm{M}}, d_{\mathrm{E}}, d_{\mathrm{C}}\right\}$ for the PGA (g) interval of $[0.323,0.384] \mathrm{g}$.

TABLE 5: Certainty measure of damage sets in equation (16) using equation (12) based on the possibility distribution in Figure 4.

\begin{tabular}{lccccc}
\hline PGA interval $(\mathrm{g})\left[\theta_{1}, \theta_{2}\right]$ & None $(N)(\%)$ & Slight $(S)(\%)$ & Moderate $(M)(\%)$ & Extensive $(E)(\%)$ & Collapse $(C)(\%)$ \\
\hline$[0.069,0.079]$ & 100.0 & 0.00 & 0.0 & 0.0 & 0.0 \\
{$[0.080,0.137]$} & 100.0 & 2.23 & 0.0 & 0.0 & 0.0 \\
{$[0.138,0.322]$} & 100.0 & 3.36 & 1.8 & 2.4 & 0.0 \\
{$[0.323,0.384]$} & 100.0 & 17.67 & 19.7 & 6.9 & 0.0 \\
{$[0.385,0.680]$} & 100.0 & 27.30 & 36.7 & 18.7 & 0.3 \\
{$[0.682,0.889]$} & 100.0 & 46.76 & & \\
\hline
\end{tabular}

Table 6: Possibility measure of damage sets in equation (16) using equation (11) based on the possibility distribution in Figure 4.

\begin{tabular}{lccccc}
\hline PGA interval $(\mathrm{g})\left[\theta_{1}, \theta_{2}\right]$ & None $(N)(\%)$ & Slight $(S)(\%)$ & Moderate $(M)(\%)$ & Extensive $(E)(\%)$ & Collapse $(C)(\%)$ \\
\hline$[0.069,0.079]$ & 100.0 & 100.0 & 100.0 & 100.0 & 100.0 \\
{$[0.080,0.137]$} & 100.0 & 100.0 & 100.0 & 100.0 & 100.0 \\
{$[0.138,0.322]$} & 100.0 & 100.0 & 100.0 & 100.0 & 100.0 \\
{$[0.323,0.384]$} & 100.0 & 100.0 & 100.0 & 100.0 & 100.0 \\
{$[0.385,0.680]$} & 100.0 & 100.0 & 100.0 & 100.0 & 100.0 \\
{$[0.682,0.889]$} & 100.0 & 100.0 & 100.0 & & 100.0 \\
\hline
\end{tabular}

TABLE 7: Belief measure of damage subsets in equation (16) using equation (3) based on the degree of belief $m$ in Table 3 .

\begin{tabular}{lccccc}
\hline PGA interval $(\mathrm{g})\left[\theta_{1}, \theta_{2}\right]$ & $N(\%)$ & $S(\%)$ & $M(\%)$ & $E(\%)$ & $C(\%)$ \\
\hline$[0.069,0.079]$ & 100.0 & 0.00 & 0.0 & 0.0 & 0.0 \\
{$[0.080,0.137]$} & 100.0 & 2.23 & 0.0 & 0.0 & 0.0 \\
{$[0.138,0.322]$} & 100.0 & 3.36 & 1.8 & 0.0 & 0.0 \\
{$[0.323,0.384]$} & 100.0 & 17.67 & 8.0 & 2.4 & 0.0 \\
{$[0.385,0.680]$} & 100.0 & 27.30 & 19.7 & 6.9 & 0.3 \\
{$[0.682,0.889]$} & 100.0 & 46.76 & 36.7 & 18.7 & 3.6
\end{tabular}

TABLE 8: Plausibility measure of damage subsets in equation (16) using equation (4) based on the degree of belief $m$ in Table 3.

\begin{tabular}{lccccc}
\hline PGA interval $(\mathrm{g})\left[\theta_{1}, \theta_{2}\right]$ & $N(\%)$ & $S(\%)$ & $M(\%)$ & $E(\%)$ & $C(\%)$ \\
\hline$[0.069,0.079]$ & 100.0 & 100.0 & 100.0 & 100.0 & 100.0 \\
{$[0.080,0.137]$} & 100.0 & 100.0 & 100.0 & 100.0 & 100.0 \\
{$[0.138,0.322]$} & 100.0 & 100.0 & 100.0 & 100.0 & 100.0 \\
{$[0.323,0.384]$} & 100.0 & 100.0 & 100.0 & 100.0 & 100.0 \\
{$[0.385,0.680]$} & 100.0 & 100.0 & 100.0 & 100.0 & 100.0 \\
{$[0.682,0.889]$} & 100.0 & 100.0 & 100.0 & 100.0 & 100.0 \\
\hline
\end{tabular}




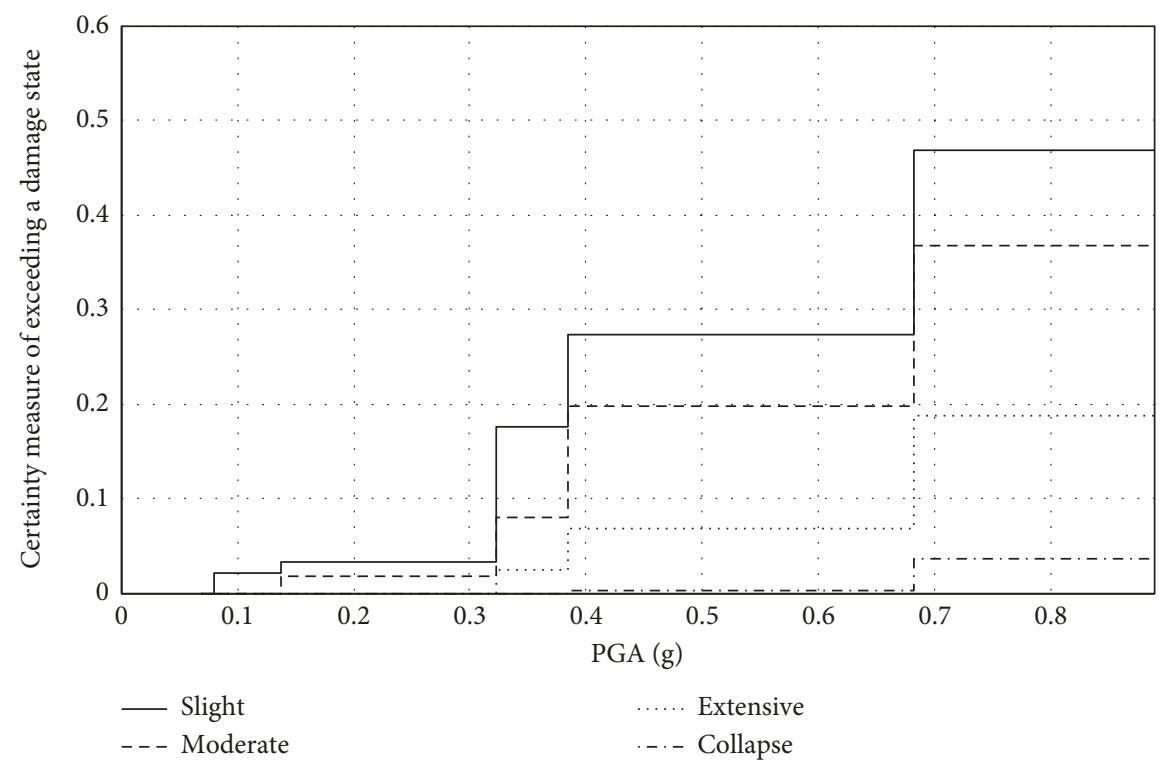

FIGURE 6: Empirical fragility curves of damage state subsets determined by measuring certainty of possibility distributions for PGA (g) intervals.

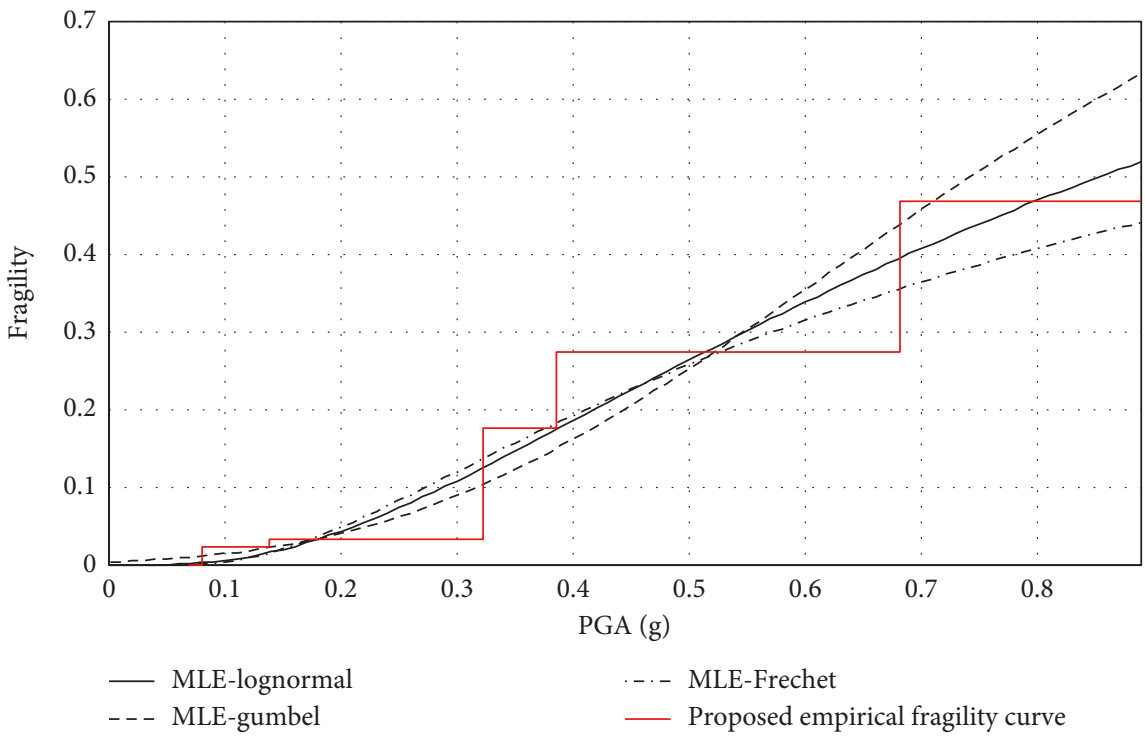

FIGURE 7: Comparison of empirical fragility curves of damage state with Slight.

formulated by connecting the necessity measure at the center of bin instead of using step function that has the same value in a PGA interval (bin). An example using "PGA bin" of $0.1 \mathrm{~g}$ is presented in Figures 11-14 for the respective damage state of "Slight," "Moderate," "Extensive," and "Collapse". In the figures, the proposed fragility curves using expert's interval are compared with those using the uniform interval. The alternative formulation of the proposed fragility curves by connecting the certainty measure at the center of PGA interval is also presented in Figures 11-14. The comparisons in the figures showed that the uniform interval would be used to generate the proposed fragility curves in this study with a large number of damage data.

\section{Conclusions}

A framework to consider the "nonspecificity" of damage data is presented. Considering that the damage states for fragility curves are generally nested to each other, the possibility theory, a special form of the evidence theory for nested intervals, is applied to generate fragility information from seismic damage data. Seismic damage data classified by four damage levels were used for a case study. Based on the damage state evidence, the degree of belief is assigned to a consonant set of damage levels. Possibility distributions for predetermined PGA region are generated using the assignment of the degree of belief. The sequence of monotone measures of each damage level 


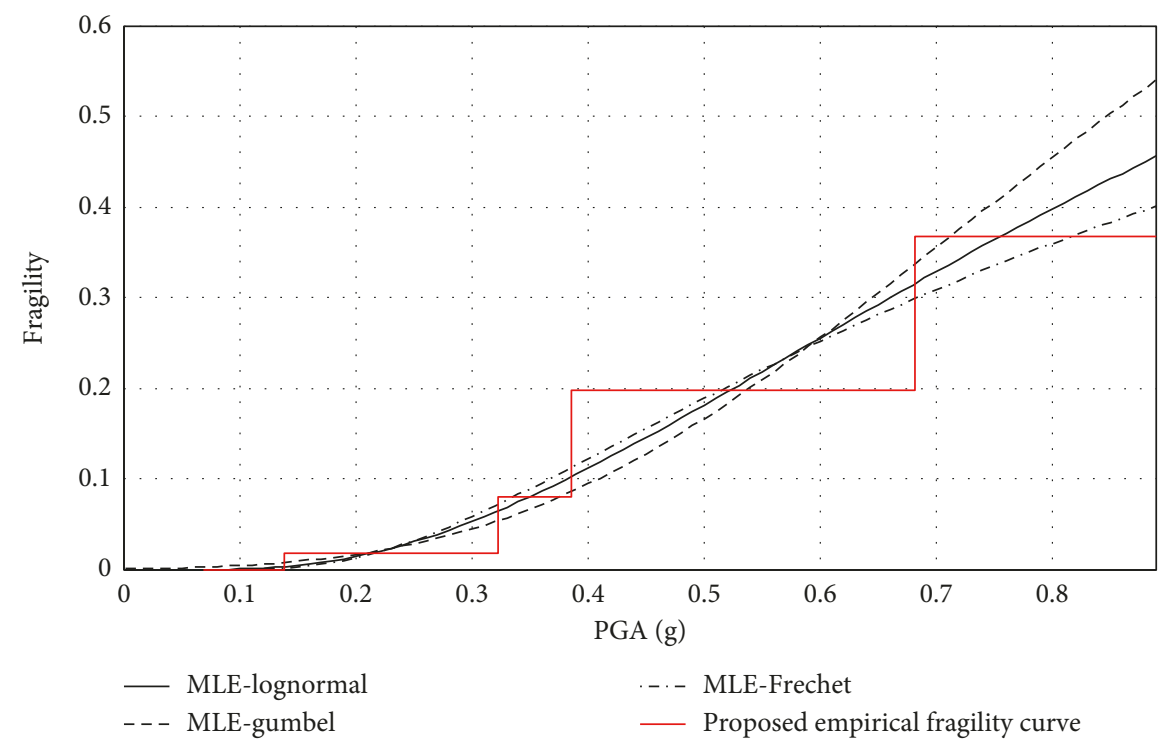

Figure 8: Comparison of empirical fragility curves of damage state with Moderate.

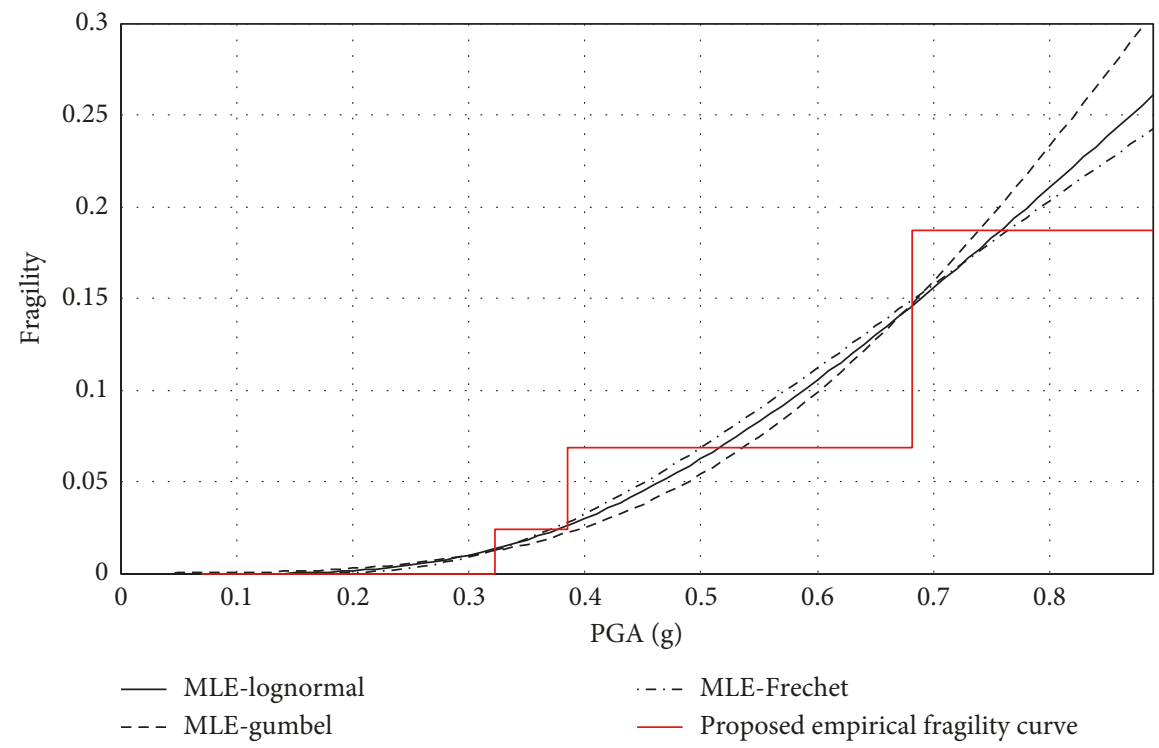

Figure 9: Comparison of empirical fragility curves of damage state with Extensive.

with respect to PGA is presented and compared with conventional fragility curves generated by maximum likelihood estimation. It was shown that the generated sequence of certainty measure could be used as fragility curves in alternative perspective. Noticeably, the fragility curves from possibility distribution represent the certainty of damage state, and those are generated without any assumption of distributions. The empirical fragility curves using possibility theory were compared with those generated by maximum likelihood estimation. The results showed that the conventional fragility curves generated by assuming the distributions overestimate the failure probability at the relatively high PGA, while those underestimate the failure probability at the medium range of PGA. Therefore, the proposed empirical fragility curves using possibility theory can be used as an alternative methodology for earthquake engineering.

\section{Appendix}

All possible subsets of a set constitute a special set defined as power set.

$$
\begin{aligned}
X & =\{a, b, c\}, \\
P(X) & =\{\varnothing,\{a\},\{b\},\{c\},\{a, b\},\{b, c\},\{a, c\},\{a, b, c\}\} .
\end{aligned}
$$

Example 1. Evidence theory.

Consider a discrete universe $X=\{1,2,3\}$. The degree of belief (evidence) $m$ is assigned to the corresponding power set 


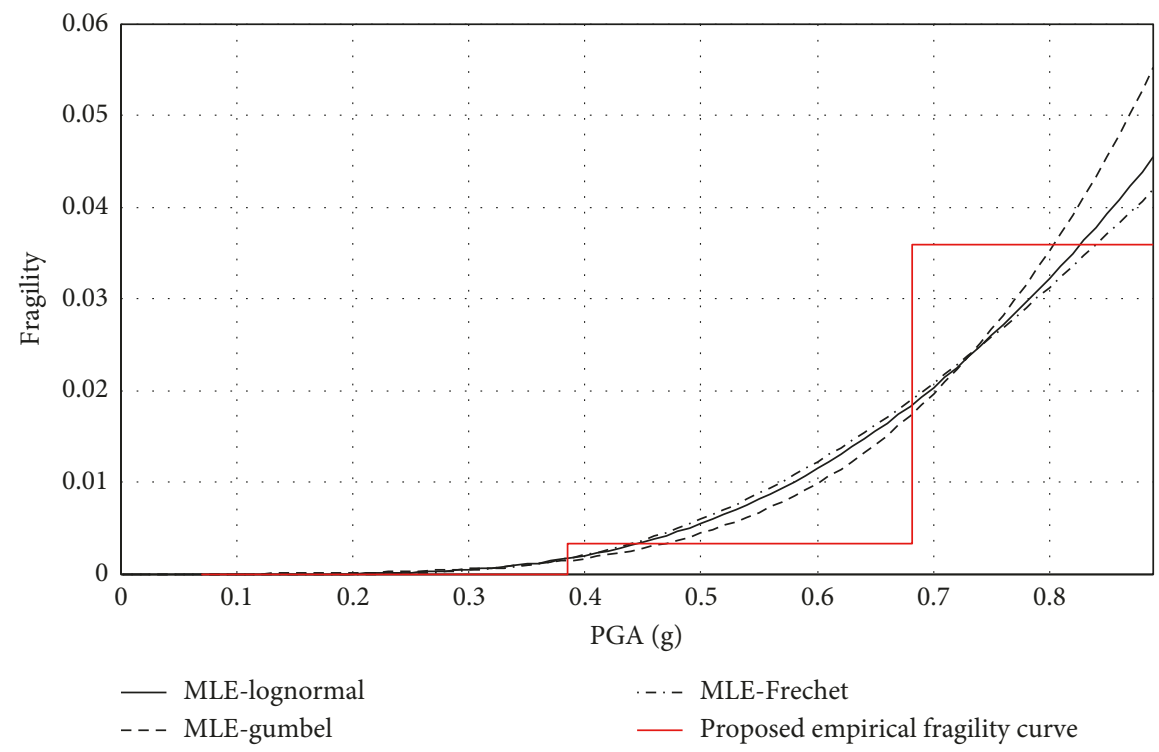

Figure 10: Comparison of empirical fragility curves of damage state with Collapse.

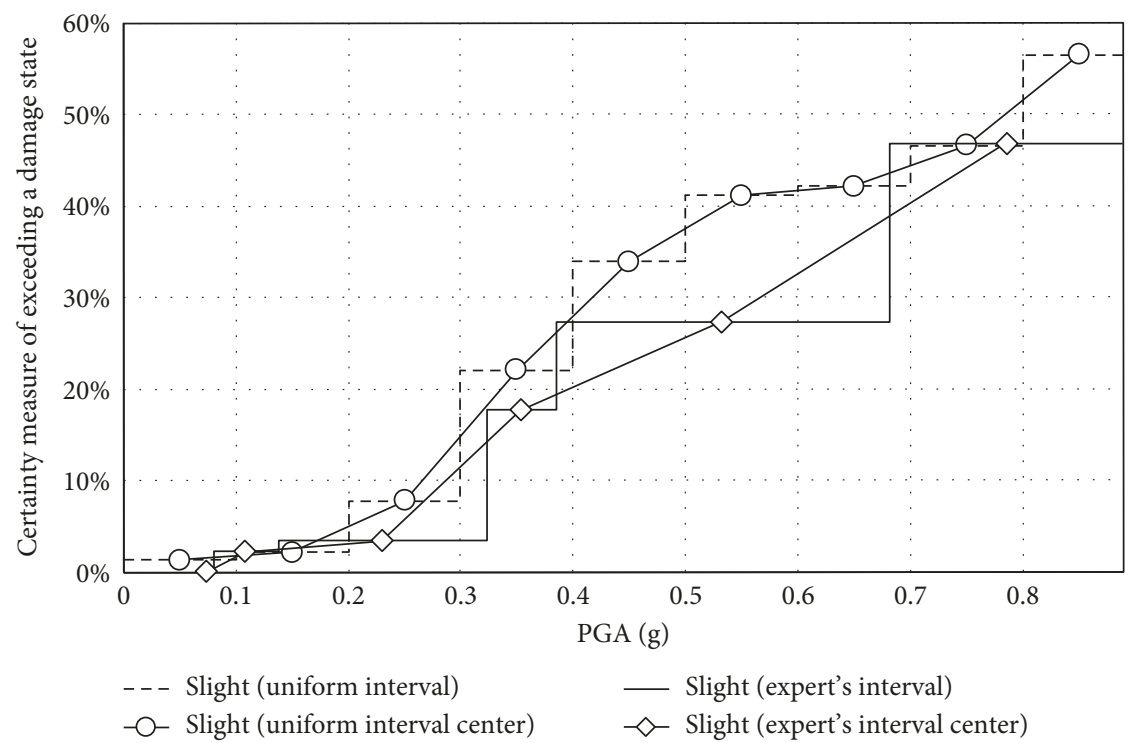

FIGURE 11: Comparison of the proposed fragility curves for Slight about the different interval selections with alternative formulation of the proposed fragility curves by using step function and connecting the necessity measure at the center of PGA interval.

with the summation of $m$ as unity as shown in equation (2) such as

$$
\begin{aligned}
P(X) & =\{\varnothing,\{1\},\{2\},\{3\},\{1,2\},\{2,3\},\{1,3\},\{1,2,3\}\} \\
\longrightarrow m & =[0,0.1,0.1,0.1,0.2,0.1,0.1,0.3] .
\end{aligned}
$$

The monotone measures for a subset are calculated by equation (3) for belief and equation (4) for plausibility as presented in Table 9.

Example 2. Special case of evidence theory (same with probability theory).
For the same universe $X$ in example 2, the degree of belief (evidence) $m$ is assigned to the corresponding power set such as

$$
\begin{aligned}
& P(X)=\{\varnothing,\{1\},\{2\},\{3\},\{1,2\},\{2,3\},\{1,3\},\{1,2,3\}\} \\
& \longrightarrow m=[0,0.3,0.3,0.4,0,0,0,0] .
\end{aligned}
$$

The monotone measures, belief and plausibility, are calculated as presented in Table 10 .

As shown in results, belief and plausibility measures have the same values for all subsets, and ignorance measures are 


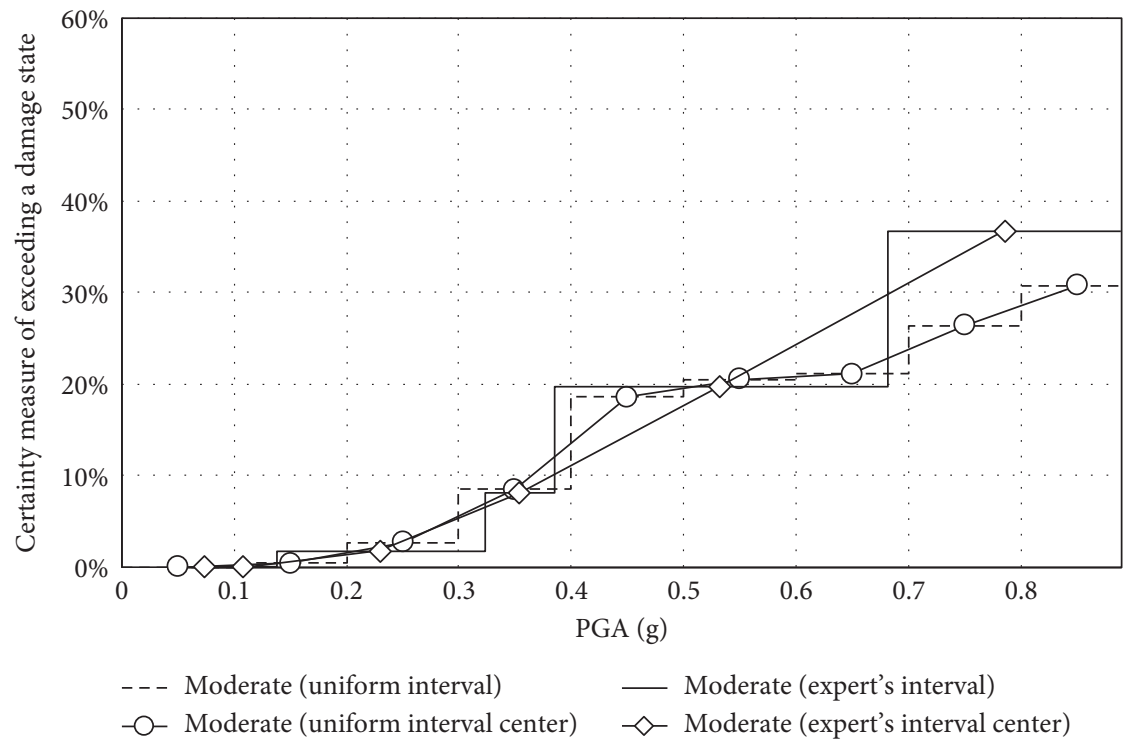

FIGURE 12: Comparison of the proposed fragility curves for Moderate about the different interval selections with alternative formulation of the proposed fragility curves by using step function and connecting the necessity measure at the center of PGA interval.

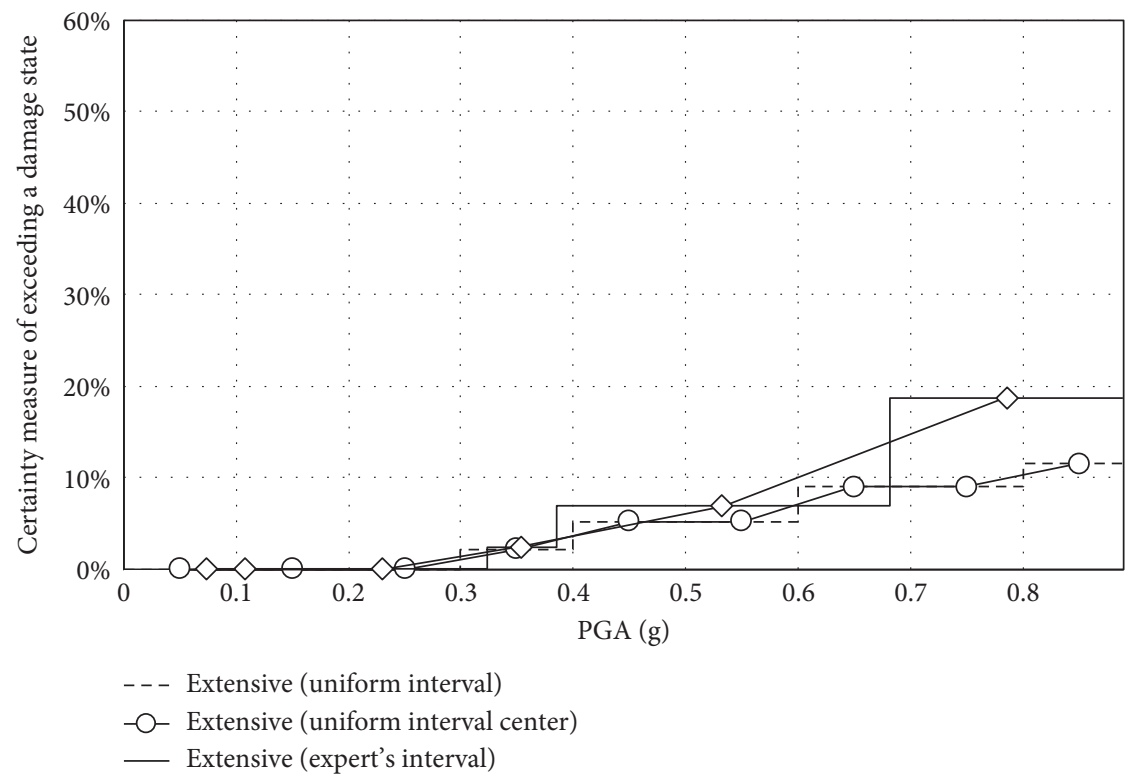

FIGURE 13: Comparison of the proposed fragility curves for Extensive about the different interval selections with alternative formulation of the proposed fragility curves by using step function and connecting the necessity measure at the center of PGA interval.

going to be zero. Therefore, belief and plausibility measures can be represented as one monotone measure such as probability.

Example 3. Special case of evidence theory (same with possibility theory).

As shown in Figure 1, if a body of evidence is nested within each other for a discrete universe $\{a, b, c\}$, this body of evidence is called "consonant body of evidence". For a consonant body of evidence, belief and plausibility are equal to necessity and possibility, respectively.
For the same universe $X$ in example 2, when the degree of belief (evidence) $m$ is assigned to the corresponding power set such as

$$
\begin{aligned}
& P(X)=\{\varnothing,\{1\},\{2\},\{3\},\{1,2\},\{2,3\},\{1,3\},\{1,2,3\}\} \\
& \longrightarrow m=[0,0.3,0,0,0.3,0,0,0.4] .
\end{aligned}
$$

The monotone measures, belief and plausibility, are calculated as presented in Table 11. Moreover, possibility distributions can be generated using equation (10) as presented in Table 12. Using these possibility distributions in 


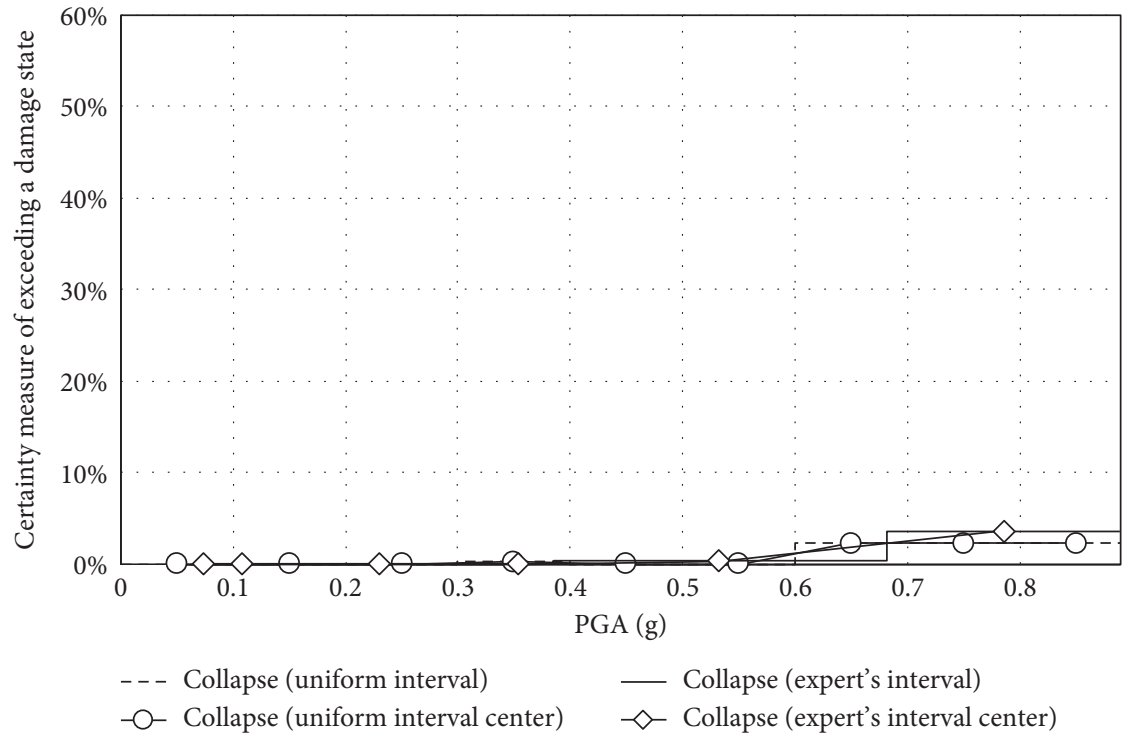

FIGURE 14: Comparison of the proposed fragility curves for Collapse about the different interval selections with alternative formulation of the proposed fragility curves by using step function and connecting the necessity measure at the center of PGA interval.

TABLE 9: The calculated monotone measures in evidence theory.

\begin{tabular}{|c|c|}
\hline Subset & Monotone measures in evidence theory \\
\hline$\{1\}$ & $\begin{array}{c}\operatorname{bel}(\{1\})=m(\{1\})=0 \\
\operatorname{pl}(\{1\})=m(\{1\})+m(\{1,2\})+m(\{1,3\})+m(\{1,2,3\}) \\
=0.1+0.2+0.1+0.3=0.7 \\
\operatorname{ign}(\{1\})=\operatorname{pl}(\{1\})-\operatorname{bel}(\{1\})=0.7-0.1=0\end{array}$ \\
\hline$\{1,2\}$ & $\begin{array}{c}\operatorname{bel}(\{1,2\})=m(\{1\})+m(\{2\})+m(\{1,2\})=0.4 \\
\operatorname{pl}(\{1,2\})=m(\{1\})+m(\{2\})+m(\{1,2\})+m(\{2,3\})+ \\
m(\{1,3\})+m(\{1,2,3\})=1 \\
\operatorname{ign}(\{1,2\})=\operatorname{pl}(\{1,2\})-\operatorname{bel}(\{1,2\})=1-0.4=0.6\end{array}$ \\
\hline$\{1$, & $\begin{array}{c}\operatorname{bel}(\{1,2,3\})=\text { all }=1 \\
\operatorname{pl}(\{1,2,3\})=\text { all }=1\end{array}$ \\
\hline
\end{tabular}

TABLE 10: The calculated monotone measures in a special case of evidence theory which is the same with probability theory.

\begin{tabular}{|c|c|}
\hline Subset & Monotone measures in evidence theory \\
\hline$\{1\}$ & $\begin{array}{c}\operatorname{bel}(\{1\})=m(\{1\})=0.3 \\
\operatorname{pl}(\{1\})=m(\{1\})+m(\{1,2\})+m(\{1,3\})+m(\{1,2,3\}) \\
=0.3+0+0+0=0.3 \\
\operatorname{ign}(\{1\})=\operatorname{pl}(\{1\})-\operatorname{bel}(\{1\})=0.3-0.3=0\end{array}$ \\
\hline$\{1$, & $\begin{array}{c}\operatorname{bel}(\{1,2\})=m(\{1\})+m(\{2\})+m(\{1,2\})=0.3+0.3+ \\
0=0.6 \\
\operatorname{pl}(\{1,2\})=m(\{1\})+m(\{2\})+m(\{1,2\})+m(\{2,3\})+ \\
m(\{1,3\})+m(\{1,2,3\})=0.3+0.3+0+0+0+0=0.6 \\
\operatorname{ign}(\{1,2\})=\operatorname{pl}(\{1,2\})-\operatorname{bel}(\{1,2\})=0.6-0.6=0\end{array}$ \\
\hline$\{1,2,3\}$ & $\begin{array}{c}\operatorname{bel}(\{1,2,3\})=\text { all }=1 \\
\operatorname{pl}(\{1,2,3\})=\text { all }=1 \\
\operatorname{ign}(\{1,2,3\})=\operatorname{pl}(\{1,2,3\})-\operatorname{bel}(\{1,2,3\})=1-1=0\end{array}$ \\
\hline
\end{tabular}

Table 12, certainty and possibility measures in possibility theory are calculated using equations (11) and (12) as presented in Table 13. As expected, the belief and plausibility measures in Table 11 are equal to the certainty and possibility measures in Table 13 respectively.
TABLE 11: The calculated monotone measures in a special case of evidence theory which is the same with possibility theory.

\begin{tabular}{|c|c|}
\hline Subset & Uili \\
\hline$\{1\}$ & $\begin{array}{c}\operatorname{bel}(\{1\})=m(\{1\})=0.3 \\
\operatorname{pl}(\{1\})=m(\{1\})+m(\{1,2\})+m(\{1,3\})+m(\{1,2,3\}) \\
=0.3+0.3+0+0.4=1 \\
\operatorname{ign}(\{1\})=\operatorname{pl}(\{1\})-\operatorname{bel}(\{1\})=1-0.3=0.7\end{array}$ \\
\hline$\{1,2\}$ & $\begin{array}{c}\operatorname{bel}(\{1,2\})=m(\{1\})+m(\{2\})+m(\{1,2\})=0.3+0+ \\
0.3=0.6 \\
\operatorname{pl}(\{1,2\})=m(\{1\})+m(\{2\})+m(\{1,2\})+m(\{2,3\})+ \\
m(\{1,3\})+m(\{1,2,3\})=0.3+0+0.3+0+0+0.4=1 \\
\operatorname{ign}(\{1,2\})=\operatorname{pl}(\{1,2\})-\operatorname{bel}(\{1,2\})=1-0.6=0.4\end{array}$ \\
\hline$\{1,2$, & $\begin{array}{c}\operatorname{bel}(\{1,2,3\})=\text { all }=1 \\
\operatorname{pl}(\{1,2,3\})=\text { all }=1 \\
\operatorname{ign}(\{1,2,3\})=\operatorname{pl}(\{1,2,3\})-\operatorname{bel}(\{1,2,3\})=1-1=0\end{array}$ \\
\hline
\end{tabular}

TABLE 12: The possibility distributions.

\begin{tabular}{lc}
\hline Subset & Monotone measures in evidence theory \\
\hline \multirow{2}{*}{1} & $\pi(\{1\})=m(\{1\})+m(\{1,2\})+m(\{1,3\})+m(\{1,2,3\})=$ \\
& $0.3+0.3+0+0.4=1$ \\
\multirow{2}{*}{2} & $\pi(\{2\})=m(\{2\})+m(\{1,2\})+m(\{2,3\})+m(\{1,2,3\})=$ \\
& $0+0.3+0+0.4=0.7$ \\
\multirow{2}{*}{3} & $\pi(\{3\})=m(\{3\})+m(\{1,3\})+m(\{2,3\})+m(\{1,2,3\})=$ \\
& $0+0+0+0.4=0.4$
\end{tabular}

TABLE 13: The calculated monotone measures in possibility theory.

\begin{tabular}{|c|c|}
\hline Subset & Monotone measures in possibility theory \\
\hline$\{1\}$ & $\begin{array}{c}\operatorname{cert}(\{1\})=1-\sup [\pi(\{2\}), \pi(\{3\})]=1-\sup [0.7,0.4] \\
=0.3 \\
\operatorname{pos}(\{1\})=\pi(\{1\})=1\end{array}$ \\
\hline$\{1,2\}$ & $\begin{array}{c}\operatorname{cert}(\{1,2\})=1-\pi(\{3\})=1-0.4=0.6 \\
\operatorname{pos}(\{1,2\})=\sup [\pi(\{1\}), \pi(\{2\})]=\sup [1,0.7]=1\end{array}$ \\
\hline
\end{tabular}

$\{1,2,3\} \quad \operatorname{pos}(\{1,2,3\})=\sup [\pi(\{1\}), \pi(\{2\}), \pi(\{3\})]=\sup [1$, $0.7,0.4]=1$ 


\section{Data Availability}

The data used for the case study of this study can be found in Reference [16].

\section{Conflicts of Interest}

The author declares that there are no conflicts of interest.

\section{Acknowledgments}

This work was supported by Kyungnam University Foundation Grant, 2016.

\section{References}

[1] C. O. Li and R. E. Melchers, "Time-dependent reliability analysis of corrosion-induced concrete cracking," $A C I$ Structural Journal, vol. 102, no. 4, pp. 543-549, 2005.

[2] J. Seo, G. Hatfield, and J.-H. Kimn, "Probabilistic structural integrity evaluation of a highway steel bridge under unknown trucks," Journal of Structural Integrity and Maintenance, vol. 1, no. 2, pp. 65-72, 2016.

[3] D. Dubois, "Possibility theory and statistical reasoning," Computational Statistics and Data Analysis, vol. 51, no. 1, pp. 47-69, 2006.

[4] T. J. Ross, Fuzzy Logic with Engineering Applications, John Wiley \& Sons, Hoboken, NJ, USA, 3rd edition, 2010.

[5] G. J. Klir and B. Yuan, Fuzzy Sets and Fuzzy Logic, Theory and Applications, Prentice-Hall, Upper Saddle River, NJ, USA, 1995.

[6] G. J. Klir, Uncertainty and Information, John Wiley \& Sons, Hoboken, NJ, USA, 2006.

[7] O. F. Hoffman and J. S. Hammonds, "Propagation of uncertainty in risk assessment: the need to distinguish between uncertainty due to lack of knowledge and uncertainty due to variability," Risk Analysis, vol. 14, no. 5, pp. 707-712, 1994.

[8] J. C. Helton and D. E. Burmaster, "Guest editorial: treatment of aleatory and epistemic uncertainty in performance assessments for complex systems," Reliability Engineering and System Safety, vol. 54, no. 2-3, pp. 91-94, 1996.

[9] H. G. Matthies, C. E. Brenner, C. G. Bucher, and C. Guedes Soares, "Uncertainties in probabilistic numerical analysis of structures and solids-stochastic finite elements," Structural Safety, vol. 19, no. 3, pp. 283-336, 1997.

[10] W. L. Oberkampf, S. M. DeLand, B. M. Rutherford, K. V. Diegert, and K. F. Alvin, "Error and uncertainty in modeling and simulations," Engineering and System Safety, vol. 75, no. 3, pp. 333-357, 2002.

[11] A. P. Dempster, "Upper and lower probabilities induced by a multivalued mapping," Annals of Mathematical Statistics, vol. 38, no. 2, pp. 325-339, 1967.

[12] G. Shafer, Mathematical Theory of Evidence, Princeton University Press, Princeton, NJ, USA, 1976.

[13] D. Dubois and H. Prade, Possibility Theory: An Approach to Computerized Processing of Uncertainty, Plenum Press, New York, NY, USA, 1988.

[14] L. A. Zadeh, "Fuzzy sets," Information and Control, vol. 8, no. 3, pp. 338-353, 1965.

[15] L. A. Zadeh, "Fuzzy sets as a basis for a theory of possibility," Fuzzy Sets and Systems, vol. 1, no. 1, pp. 3-28, 1978.
[16] M. Shinozuka, M. O. Feng, H. Kim, T. Uzawa, and T. Ueda, Statistical Analysis of Fragility Curves, Technical report MCEER, Federal Highway Administration, Washington, DC, USA, 2001.

[17] F. Colangelo, "A simple model to include fuzziness in the seismic fragility curve and relevant effect compared with randomness," Earthquake Engineering and Structural Dynamics, vol. 41, no. 5, pp. 969-986, 2012.

[18] J. Rohmer and C. Baudrit, "The use of the possibility theory to investigate the epistemic uncertainties within scenario-based earthquake risk assessments," Natural Hazards, vol. 56, no. 3, pp. 613-632, 2010.

[19] T. Rossetto and A. Elnashai, "Derivation of vulnerability functions for European-type RC structures based on observational data," Engineering Structures, vol. 25, no. 10, pp. 1241-1263, 2003.

[20] C. Del Gaudio, G. De Martino, M. De Ludovico et al., "Empirical fragility curves from the damage data on RC buildings after the 2009 L'Aquila earthquake," Bulletin of Earthquake Engineering, vol. 15, no. 4, pp. 1425-1450, 2017.

[21] B. Bessason and J. O. Bjarnason, "Seismic vulnerability of lowrise residential buildings based on damage data from three earthquakes (MW 6.5, 6.5 and 6.3)," Engineering Structures, vol. 111, pp. 64-79, 2016.

[22] D. Gautam, G. Fabbrocino, and F. Santucci de Magistris, "Derive empirical fragility functions for Nepali residential buildings," Engineering Structures, vol. 171, pp. 612-628, 2018.

[23] D. Gautam, "Observational fragility functions for residential stone masonry buildings in Nepal," Bulletin of Earthquake Engineering, vol. 16, no. 10, pp. 4661-4673, 2018.

[24] M. Rota, A. Penna, and C. L. Strobbia, "Processing Italian damage data to derive typological fragility curves," Soil Dynamics and Earthquake Engineering, vol. 28, no. 10-11, pp. 933-947, 2008.

[25] M. Colombi, B. Borzi, H. Crowley, M. Onida, F. Meroni, and R. Pinho, "Deriving vulnerability curves using Italian earthquake damage data," Bulletin of Earthquake Engineering, vol. 6, no. 3, pp. 485-504, 2006.

[26] J. J. Kim, "Uncertainty quantification in serviceability of reinforced concrete structures," PhD Dissertation in University of New Mexico, USA, 2009.

[27] J. J. Kim, M. M. Reda Taha, and T. J. Ross, "Establishing concrete cracking strength interval using possibility theory with an application to predict the possible reinforced concrete deflection interval," Engineering Structures, vol. 32, no. 11, pp. 3592-3600, 2010.

[28] J. J. Kim, M. M. Reda Taha, and T. J. Ross, "Binary damage classification in SHM using possibility distributions," in Proceedings of the Second International Conference on Vulnerability and Risk Analysis and Management (ICVRAM) and the Sixth International Symposium on Uncertainty Modeling and Analysis, (ISUMA), Liverpool, UK, July 2014. 


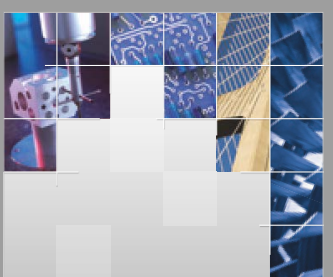

\section{Enfincering}
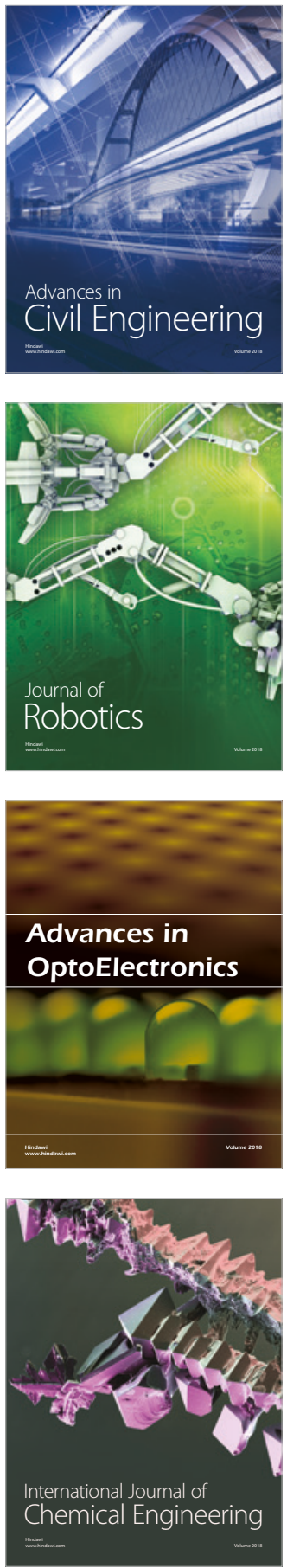

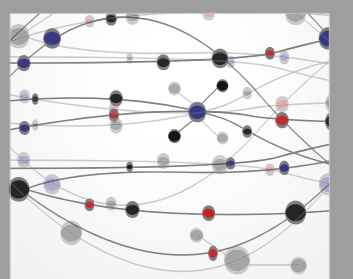

\section{Rotating \\ Machinery}

The Scientific World Journal

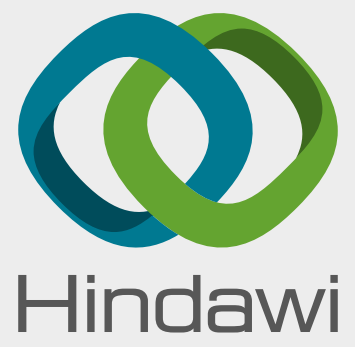

Submit your manuscripts at

www.hindawi.com
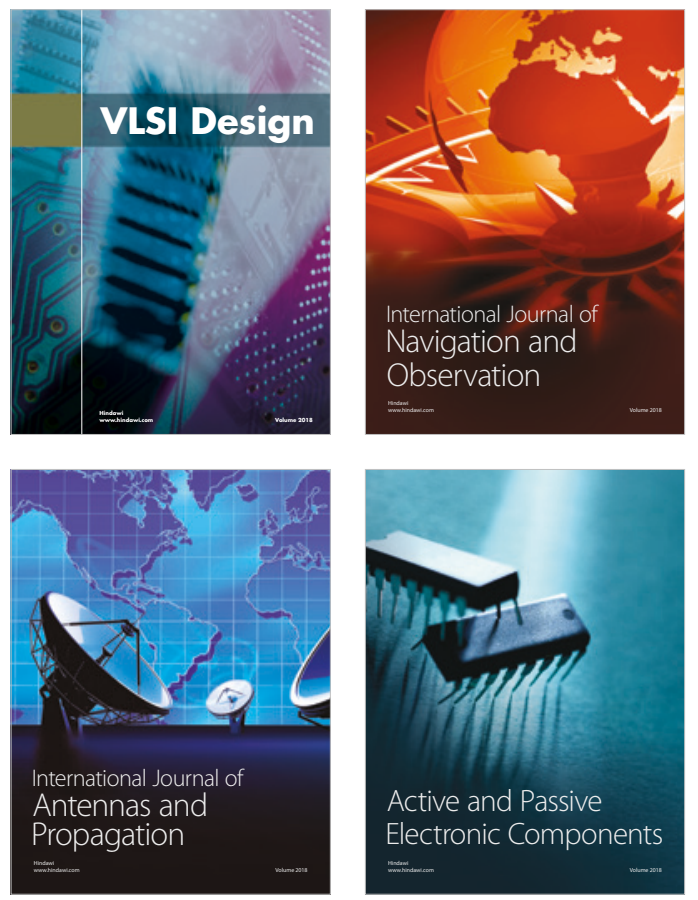
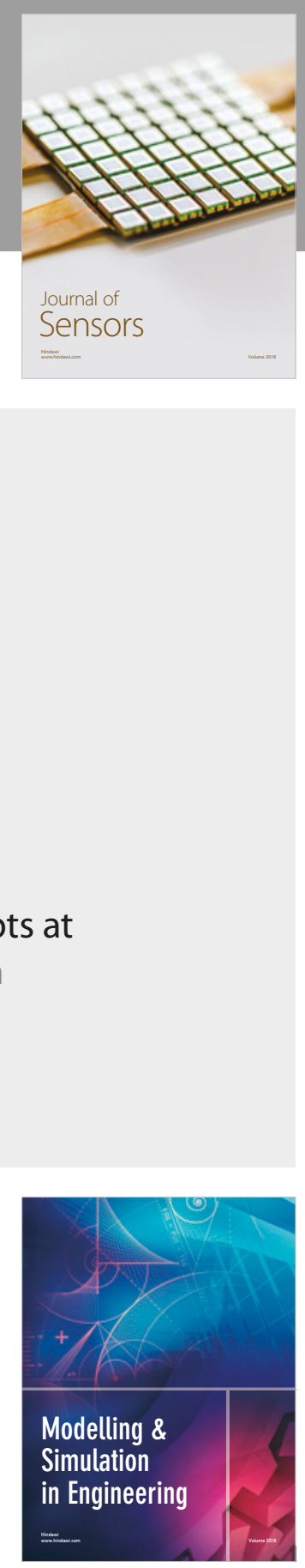

\section{Advances \\ Multimedia}
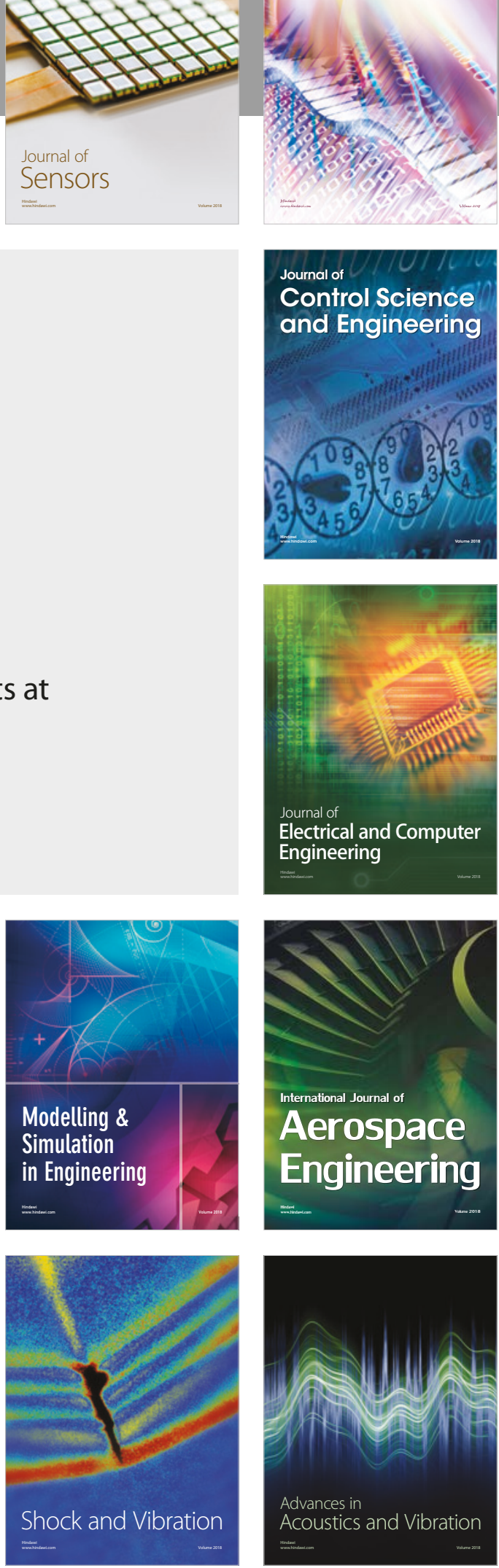